\title{
A Fundação da cidade de Belém inventada pelos pinceis artísticos
}

Igor Gonçalves Chaves ${ }^{1}$

Resumo: Este texto aborda a história da Amazônia artisticamente construída por Theodoro José da Silva Braga e exposta ao público no ano de 1908 como a "Fundação da Cidade de Belém". A criação dessa obra iconográfica se dá no período da intendência de Antônio José de Lemos e pouco mais de uma década após o início da República no Brasil. Trata-se de um contexto profícuo para a produção das artes visuais na cidade de Belém, sendo que o pintor Theodoro Braga se destaca no mundo das artes e da intelectualidade belenense no início do século XX.

Palavras-chave: iconografia, arte, Amazônia.

No início do século XX, a cidade de Belém do Pará experimentava o processo de ebulição no meio artístico, o qual em certa medida se liga, substancialmente, ao momento do boom da economia da borracha, a Belle époque como o período (18701910) ficou notoriamente conhecido na historiografia da Amazônia. A vinda de artistas de várias regiões brasileiras e também do exterior torna-se ponto emblemático para a constituição da "civilização" na Amazônia, uma imagem fortemente evocada pelo poder público paraense para demonstrar a evolução da sociedade local. $\mathrm{O}$ foco deste texto delimita-se à cidade de Belém, capital do estado do Pará e centro urbano projetado ao mundo como a pequena Paris dos trópicos, ou seja, a representação da cidade moderna, antro da civilização e do progresso, que se pretendia construir sobre a capital paraense.

O intendente municipal na década de 1900 era Antônio José de Lemos que se destacou enquanto liderança política na Belém republicana do início do século XX. Antônio Lemos desempenha papel fundamental na fomentação do meio artístico belenense sendo sua a encomenda de uma série de pinturas que reproduzem alguns dos principais logradouros da cidade amazônica como a Catedral da Sé e a Praça da República. Tal feito inaugura a fase de encomendas da intendência municipal e

\footnotetext{
${ }^{1}$ Estudante de pós-graduação (mestrado) no Programa de Pós-graduação em História Social da Amazônia da Universidade Federal do Pará. Contato: igorgchaves@yahoo.com.br
} 
cristaliza a figura do senador Antônio Lemos como mecenas das artes ${ }^{2}$. Essa postura de apreciador e incentivador do mundo das artes, promovida pelo senador, contribuiria para solidificar o mecenato como postura própria das lideranças políticas da região amazônica, comprovando o refinamento intelectual das mesmas e o lugar da cidade de Belém, segundo alguns viajantes estrangeiros, enquanto um dos principais centros culturais do país 3 .

É justamente um dos protegidos do intendente municipal que irá impactar o cenário artístico da capital paraense com a exposição de uma de suas obras no ano de 1908, a qual carrega em si grande valor simbólico para a memória/história de Belém. O homem em questão é Theodoro José da Silva Braga, artista paraense e considerado um profissional ilustre pelos intelectuais da época. A que se deve esse renome? Principalmente a formação da carreira do senhor Theodoro Braga: diplomado pela Faculdade de Direito do Recife em 1893; discípulo de Jerônimo Teles Junior, JeanPaul Laurens e outros; estudante do curso de pintura da Escola Nacional de Belas Artes do Rio de Janeiro; aluno laureado com o prêmio de viagem à Europa em 1899, onde permaneceu como pensionista por cinco anos visitando instituições de formação artística e estabelecendo contato com mestres europeus. Não é estranho, portanto, a criação de expectativas em torno do jovem paraense tendo em vista as referências que ele construiu ao longo de sua formação e o que o historiador Aldrin Moura de Figueiredo considera uma rápida evolução em meio aos novos talentos nacionais4. Após o fim de sua pensão na Europa, o senhor Theodoro Braga retornaria a Belém para firmar-se enquanto um "nome de influência” nas artes visuais do Pará. No dia 16 de outubro de 1906, o senhor Braga já inaugurava sua terceira exposição de pinturas compondo aquarelas dedicadas aos "cantos pitorescos e antigos da cidade de Belém" 5. Após essa temporada prolífera e bem avaliada em 1906, o artista paraense seria convocado a executar o trabalho que culminaria na composição de uma de suas obras capitais. Sob o pedido e encomenda do intendente municipal Antônio Lemos, o senhor Theodoro Braga deveria confeccionar uma tela representativa da gênese da

2 FIGUEIREDO, Aldrin Moura de. Eternos modernos: uma história social da arte e da literatura na Amazônia, 1908-1929. 09/11/2001. 315 folhas. Tese de doutorado. Instituto de Filosofia e Ciências Humanas, Unicamp, Campinas-SP, 2001.

${ }^{3}$ COUDREAU, Henri. L'Ave nir de la capitale du Pará. Anais da Biblioteca e Arquivo Público do Pará. V.8. Belém, 1913

${ }^{4}$ FIGUEIREDO, Aldrin Moura de. Eternos modernos: uma história social da arte e da literatura na Amazônia, 1908-1929. 09/11/2001. 315 folhas. Tese de doutorado. Instituto de Filosofia e Ciências Humanas, Unicamp, Campinas-SP, 2001, p. 49.

${ }^{5}$ BRAGA, Theodoro. "A arte no Pará (1888-1918) retrospectiva histórica dos últimos trinta anos". Revista do Instituto Histórico e Geográfico do Pará, vol. 8, 1934, p. 149-159. 
cidade de Belém. Desse modo, depois de encerrada a terceira exposição de aquarelas, no mês de novembro de 1906 o artista embarcaria para Lisboa, retornando à Europa dessa vez na qualidade de profissional consolidado e com o intuito de investigar os arquivos, os documentos e os registros sobre o início da colonização portuguesa na Amazônia.

Nesse ponto é necessário salientar a relevância dada por Theodoro Braga à pesquisa documental. Esse indivíduo, além de profissional das artes também se traveste de pesquisador da história, recorrendo aos vestígios do passado para construir uma obra imagética na qual será exposta uma versão desse passado. Tal ocorrência não é exclusiva dessa fase da carreira de Theodoro Braga, pois o mesmo foi sócio de instituições dedicadas à história, à geografia e à arqueologia no Brasil - a saber, o Instituto Histórico e Geográfico do Pará, o Instituto Histórico e Geográfico do Ceará, o Instituto Histórico e Geográfico do Rio Grande do Norte e o Instituto Arqueológico de Pernambuco -, além disso, ele publicou as Apostilas de História do Pará e lecionou em estabelecimentos de ensino e formação profissional em Belém. Como é possível perceber, o artista belenense construiu para si uma interessante imagem, qual seja a de um intelectual que é pintor, historiador, pesquisador e professor. Não é exclusividade e nem ineditismo essa pluralidade de atuações em Theodoro Braga, outros seguem essa linha de artista-erudito como é o caso do paulistano Benedito Calixto que se dedicou a longas pesquisas sobre o período colonial do estado de São Paulo6 ${ }^{6}$ Podemos supor que Theodoro da Silva Braga tenha herdado o posicionamento de pintor-historiador de seus mestres na Escola de Belas Artes e na Europa, pois a tradição do artista que se envereda pelos arquivos em busca de registros pretéritos para suas composições remete ao final do século XVIII7. Tratase de um diálogo entre disciplinas distintas, uma fornecedora do fato ocorrido e outra recriadora desse fato por meio dos pincéis e das tintas. Theodoro Braga, portanto, se encaixa entre esses homens das artes cuja dinâmica e a exigência da profissão os levou a outras searas como a história e a arqueologia. Nas palavras de Peter Burke:

Esses pintores podem ser vistos como historiadores de pleno direito. Eles aprenderam a partir do trabalho dos historiadores profissionais que eram

\footnotetext{
${ }^{6}$ Para a análise da obra de Benedito Calixto ver:ALVES, Caleb Faria. Benedito Calixto e a construção do imaginário republicano. Bauru: Edusc, 2003. Também uma boa parte das pesquisas de Calixto está hoje disponível no Arquivo Público do Estado de São Paulo.

7 PARET, Peter. Imagined Battles: Reflections of War in European Art.Chapel Hill: University of North Caroline Press, 1997.
} 
encontrados em número cada vez maior nas universidades do século XIX, mas fizeram também suas contribuições para a interpretação do passado. A história que eles, frequentemente, representavam era a história nacional, movida pelo nacionalismo ${ }^{8}$.

No Brasil, a pintura de história ganha lugar com a Academia Imperial de Belas Artes, instituição que surgiria por volta de 1820 como um fruto da Missão Artística Francesa de 1816. Naquele momento de mudança de status dos antigos domínios coloniais a Reino Unido de Portugal, Brasil e Algarves, fazia-se necessário inventar e reproduzir as imagens da realeza lusitana agora sediada no Rio de Janeiro, a fim de dar-lhe visibilidade frente ao mundo, bem como fornecer os símbolos oficiais para a sociedade9. Em 1822, com a independência e o surgimento do Brasil enquanto império/nação demandava a criação de símbolos capazes de transmitir e solidificar o novo status, ou melhor, fortalecer a ideia de uma nação que começava a se inventar. A pintura de história forneceria os símbolos iconográficos da nação e a Academia Imperial forneceria os profissionais habilitados para a construção desses símbolos. Entre os alunos formados pela instituição dois podem ser citados pela fama que ganhariam na segunda metade do século XIX: Pedro Américo e Victor Meirelles. Ao longo de suas carreiras ambos estariam envolvidos em confecções voltadas para o tema nacional, afinal seria o relacionamento com o nacionalismo que moveria e motivaria muitos dos pintores historiadores e a pintura histórica ${ }^{10}$. Meirelles e Américo construiriam representações de acontecimentos considerados relevantes para a história de uma nação que se inventava e precisava afirmar-se não apenas no cenário externo, mas principalmente no seu próprio cenário interno. Essas representações ao pincel deveriam figurar na memória/história do Brasil, tais como $O$ grito do Ipiranga (1888), A primeira missa do Brasil (1860), A Batalha dos Guararapes (1879) e A Batalha do Avaí (1877), telas onde o passado recente ao distante era recriado, recebendo novos significados e a Academia Imperial daria suporte a uma tradição de pintura, pautada nos cânones do que era considerada a "boa arte" europeia, e mantendo conexão com o Velho Mundo através de prêmios de viagem à Europa. A instituição sobreviveria ao fim do Império e da monarquia em

\footnotetext{
${ }^{8}$ BURKE, Peter. Testemunha ocular: história e imagem. $2^{\circ}$ edição. Bauru - São Paulo: EDUSC, 2004, p. 198.

9 SCHWARCZ, Lilia Moritz. "Os franceses no Brasil de D. João". REVISTA USP, n.79, São Paulo, 2008, p.54-69.

${ }^{10}$ BURKE, Peter. Testemunha ocular: história e imagem. $2^{\circ}$ edição. Bauru - São Paulo: EDUSC, 2004.
} 
1889, renomeada como Escola Nacional de Belas Artes, permanecendo como instituição de formação acadêmica para artistas.

Em 17 de dezembro de 1908, Theodoro José da Silva Braga, de volta à terra natal após o tempo de pesquisas na Europa, realizava sua quarta exposição artística no salão do Theatro da Paz, apresentando mais de oitenta trabalhos, dentre eles a sua grande tela histórica intitulada A Fundação da Cidade de Belém do Pará.

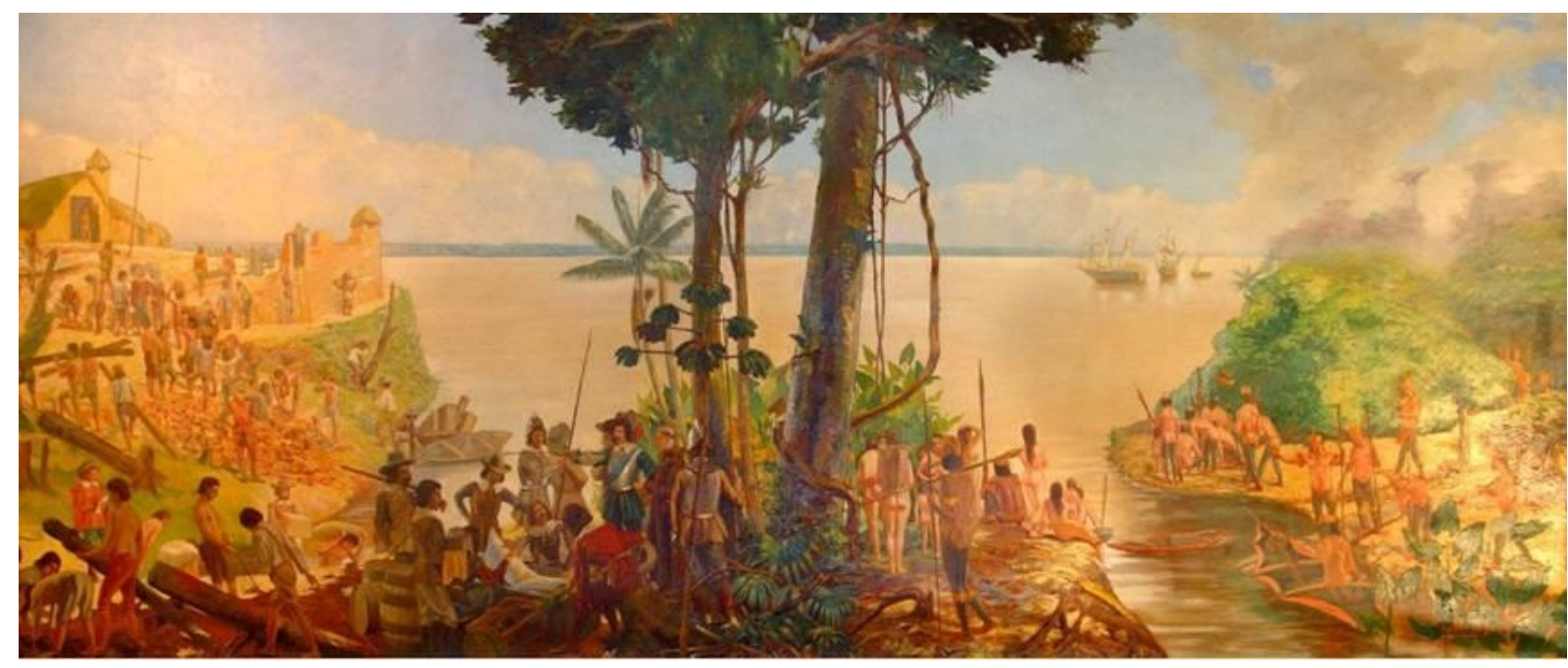

Figura 1: A Fundação da cidade de Belém, Theodoro Braga, óleo s/tela, 504 x 226 cm, 1908. Acervo do Museu de Arte de Belém. A grande tela histórica encomendada por Antônio Lemos ao pintor paraense Theodoro Braga representando as origens de Belém no século XVII é uma importante construção da história da sociedade amazônica por meio da narrativa visual da arte. Atualmente se encontra na Prefeitura de Belém, onde funciona o museu da cidade.

Com $226 \mathrm{~cm}$ de largura por $504 \mathrm{~cm}$ de comprimento, o óleo sobre tela que retrata a fundação da capital paraense foi apresentado ao público às dez horas da manhã na data acima descrita. Enquanto obra de arte de tema histórico, suas largas dimensões contêm uma interessante composição de cenas: dois momentos diferentes divididos por duas grandes árvores que ornamentam o centro da tela. No lado direito o espectador pode ver os índios tupinambá aglomerados nas duas margens de um igarapé que posteriormente se tornaria o Ver-o-Peso ${ }^{11}$, eles observam ao longe a chegada de três embarcações portuguesas "que trazem a expedição civilizadora"12. No

\footnotetext{
${ }^{11}$ BRAGA, Theodoro. A fundação da cidade de Nossa Senhora de Belém do Pará: estudos e documentos para a execução da grande tela histórica pintada pelo autor e encomendada pelo benemérito intendente municipal de Belém Exmo. Sr. Senador Antonio J. Lemos. Belém: Secção de Obras d'A Província do Pará, 1908.

12 BRAGA, Theodoro. A fundação da cidade de Nossa Senhora de Belém do Pará. estudos e documentos para a execução da grande tela histórica pintada pelo autor e encomendada pelo
} 
lado esquerdo um grande número de pessoas se ocupa no trabalho de construção do futuro Forte do Presépio; ao fundo uma igreja de taipa e palha já demarca o início da "civilização". Ao centro e em primeiro plano, à sombra das grandes embaúbas e seringueiras, está Francisco Caldeira Castelo Branco, comandante expedicionário, em momento de reunião com o seu estado-maior para definir o planejamento futuro da viagem de Pedro Teixeira ao Maranhão.

A composição das cenas nos leva a perceber o aspecto narrativo empregado na construção da tela. Quando o olhar do espectador segue o traçado da direita para a esquerda pode ler a história da gênese da sociedade amazônica, ou seja, a pintura é uma narrativa na qual o espectador observa a história de Belém, notando que o traçado é um processo que se desloca dos indígenas tupinambá nus e habitantes das florestas para os portugueses "senhores e conquistadores" 13 , construtores da civilização. $\mathrm{O}$ contraste entre as duas cenas parece servir perfeitamente à narrativa histórica artisticamente confeccionada por Theodoro Braga. Da paisagem florestal que predomina no lado direito para a modificação do terreno natural pelas mãos dos trabalhadores no lado esquerdo a história representada no óleo sobre tela segue claramente uma trajetória progressiva em direção ao mundo considerado civilizado, isto é, do reino selvagem das matas para a urbe moderna em estado de gestação. O mesmo é válido para os personagens presentes nas duas cenas: a sociedade dos índios tupinambá de um lado e do outro a sociedade moderna, colonizadora e cristã. Um ponto instigante a ser notado nos trabalhadores do Forte é a presença tanto de "homens brancos" quanto de indígenas, o que indica a assimilação das populações nativas ao processo civilizatório - note-se, por exemplo, o fato desses indígenas estarem trajados com roupas o que os diferencia dos outros índios tupinambá aglomerados no lado direito. A obra de arte, nesse caso, serviria também para fins instrutivos, pois através da contemplação dessa narrativa visual os espectadores, os belenenses, entrariam em contato indireto com a história de sua terra, com as origens da formação de sua sociedade, observando a evolução em direção ao progresso que se desenvolvia desde a gênese de Belém.

benemérito intendente municipal de Belém Exmo. Sr. Senador Antonio J. Lemos. Belém: Secção de Obras Raras d'A Província do Pará, 1908.

${ }^{13}$ BRAGA, Theodoro. A fundação da cidade de Nossa Senhora de Belém do Pará. estudos e documentos para a execução da grande tela histórica pintada pelo autor e encomendada pelo benemérito intendente municipal de Belém Exmo. Sr. Senador Antonio J. Lemos. Belém: Secção de Obras Raras d'A Província do Pará, 1908. 
O português colonizador desempenha papel central na história proposta pela Fundação de Theodoro Braga, pois são eles os portadores do germe civilizatório nas futuras terras paraenses. Por outro lado, o artista não deixa de fora os povos nativos da Amazônia, estes devem marcar sua presença enquanto símbolo de um tempo anterior ao progresso, um período que seria compreendido pelos conterrâneos do senhor Braga como a pré-história de Belém e da Amazônia. O papel dos índios na iconografia é, contudo, de antagonismo ao colonizador português, pois o autor do quadro explica que os nativos observam a chegada das naves lusitanas não com admiração e nem com curiosidade, mas sim com o ódio dirigido aos inimigos ${ }^{14}$. Posteriormente esses antagonistas seriam domesticados como bem indica a cena à esquerda com os indígenas ocupados em trabalhar na construção do Forte do Presépio, incapazes, portanto, de resistir ao destino da conquista. Desse modo, os objetivos da pintura de Theodoro Braga se conjugam em apresentar a origem da moderna cidade de Belém do século XX, metrópole herdeira da empreitada lusitana do século XVII. A narrativa em A Fundação forma um elo entre a cidade do intendente Antônio Lemos e o passado colonial, o qual é elaborado de modo a consolidar a imagem do presente.

A Fundação de Belém nos remete a outra pintura de tipologia histórica intitulada $A$ Conquista do Amazonas. Esta tela, em certa medida uma obra "aparentada" daquela produzida por Theodoro Braga, foi confeccionada pelo artista fluminense Antônio Diogo da Silva Parreiras e entregue alguns meses antes da exposição d'A Fundação, em 18 de janeiro de 1908. O que chama a atenção para a relação entre uma iconografia e outra, além da própria temática em comum, é o fato de $A$ Conquista do Amazonas ter sido feita sob a encomenda do governador do Estado do Pará, Augusto Montenegro, praticamente no mesmo período da encomenda do intendente Lemos. A pintura de Antônio Parreiras representa o episódio solene da posse das terras amazônicas, encarnado na leitura do ato de posse por João Gomes de Andrade, escrivão da expedição liderada por Pedro Teixeira. Esse episódio foi construído de modo a tornar-se um ponto crucial para a história do Estado do Pará. Na tela A Conquista do Amazonas os conquistadores portugueses ocupam o protagonismo e a centralidade da iconografia, demonstrando - tal como na

\footnotetext{
${ }^{14}$ BRAGA, Theodoro. A fundação da cidade de Nossa Senhora de Belém do Pará. estudos e documentos para execução da grande tela histórica pintada pelo autor e encomendada pelo benemérito intendente municipal de Belém Exmo. Sr. Senador Antonio J. Lemos. Belém: Secção de Obras Raras d' A Província do Pará, 1908.
} 
Fundação - o lugar privilegiado do europeu lusitano enquanto portador e construtor da civilidade. De fato a ideia apresentada na Conquista é de um feito épico, o marco primeiro da história paraense-amazônica e digno de ser rememorado, pois é o momento em que "se expandia o gênio aventuroso, que tanto caracterizava a raça lusitana desses famosos tempos"15.

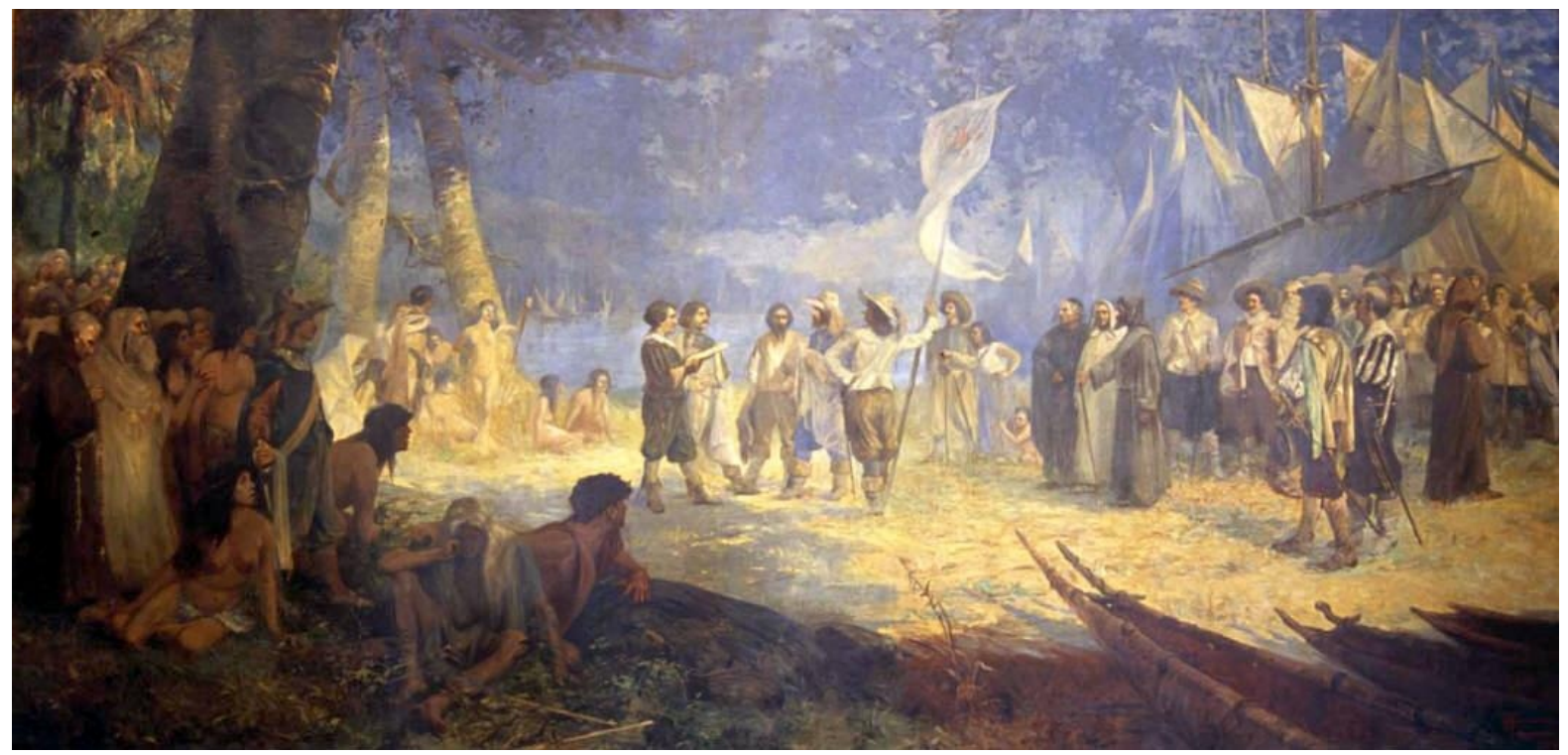

Figura 2: A Conquista do Amazonas, Antônio Diogo Parreiras, óleo s/tela, 800 x 400 cm, 1907. Acervo do Museu do Estado do Pará. Produto da encomenda do governador do Pará, esta tela apresenta similaridades com a tela histórica de Theodoro Braga. Foi uma das primeiras pinturas históricas da carreira de Antônio Parreiras. Atualmente ornamenta o antigo palácio dos governadores do Pará.

Tal como seu colega de ofício paraense, Antônio Parreiras realizaria o processo de pesquisa documental a fim de melhor representar uma cena do passado, além disso, Parreiras também gozava de certa fama profissional e apreciação por parte da elite política do Pará, o que é evidenciado pelo fato de um conjunto de oito telas de paisagem ter sido adquirido pela Intendência municipal de Belém em 1905, quando da exposição inicial do fluminense na cidade. Em A Conquista a narrativa visual preza pelo simbolismo de uma origem gloriosa, a gênese do Pará que seria inventada pela arte tal como a gênese de Belém na Fundação de 1908. Ambos os trabalhos artísticos buscam uma apropriação da história de modo a construir uma memória para a sociedade amazônica, uma memória afinada com certas perspectivas do

${ }^{15}$ PARÁ, Governador (1901-1909; Augusto Montenegro). Álbum do Estado do Pará. Paris: Chaponet, 1908.

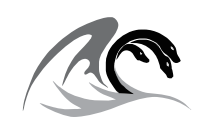


presente. Desse modo percebemos que o retrato de acontecimentos históricos e sua elevação a postos privilegiados para a demarcação das origens da civilização amazônica configuram um ponto de interesse do poder público paraense, no momento em que as lideranças estadual e municipal se preocupam em elaborar versões do passado. Esse interesse pode ser visto tanto como uma forma de criar um antepassado glorioso para a república quanto uma tentativa de fortalecer a posição de alguns grupos políticos do Pará, notadamente aqueles ligados ao intendente Antônio José de Lemos. De fato, o intendente consolidava seu lugar enquanto liderança política e o patrocínio das artes era uma de suas marcas notáveis. A postura de um homem engajado com os altos padrões da "cultura" fortificava a imagem de Lemos como um promotor da civilização na metrópole paraense e um difusor do que haveria de melhor nas belas artes. É importante atentar, por exemplo, que em 1899 o intendente adquiria a primeira grande tela do acervo municipal de Belém: Os últimos dias de Carlos Gomes, uma pintura de grandes dimensões cujo assunto é um evento histórico (o falecimento do compositor Carlos Gomes em Belém). Essa obra, feita pelos italianos Domenico De Angelis e Giovanni Capranesi formava a primeira grande aquisição do acervo da intendência e sua compra motivaria Antônio Lemos a encomendar outra grande pintura representativa da história de Belém ${ }^{16}$. A vontade do intendente seria concretizada com A Fundação, mas sabe-se que além desta, outra pintura mencionada como "Adesão do Pará à República Brasileira" fora encomendada a Aurélio de Figueiredo, irmão de Pedro Américo, com contrato firmado através da lei 484 de 11 de junho de 19077. Infelizmente não possuímos informação sobre o resultado dessa encomenda a Aurélio de Figueiredo. Contudo é perceptível o vínculo entre a criação de um patrimônio artístico - e uma arte voltada para a república - e os anseios políticos, isto é, a construção de uma boa imagem da administração de Lemos enquanto provedora de um legado "civilizado" para a Amazônia.

O óleo sobre tela de Theodoro da Silva Braga pode ser percebido e apreendido como uma representação de um acontecimento pretérito. A noção de representação aborda a questão da ausência e da presença, isto é, uma relação entre "uma coisa"

\footnotetext{
${ }^{16}$ INTÊNDENCIA Municipal de Belém. Relatório apresentado ao Conselho Municipal de Belém na sessão de 15.11.1902 pelo Exmo. Sr. Intendente Antônio José de Lemos, 1897/ 1902. Belém: A. A. Silva, 1902.

17 INTÊNDENCIA Municipal de Belém. Relatório apresentado ao Conselho Municipal de Belém na sessão de 15.11.1907 pelo Exmo. Sr. Intendente Antônio José de Lemos. Belém: A. A. Silva, 1908.
} 
ausente e a representação da mesma que assume o seu lugar. Trata-se de uma noção complexa que permeia as discussões na historiografia da cultura, sendo que não se pretende abordar tais discussões neste texto ${ }^{18}$. O termo tal como é tratado pelo historiador Carlo Ginzburg mostra-se bastante eficaz para o caso aqui estudado. A representação de algo, de uma "coisa", está ligada ao fato de essa representação assumir a presença do objeto, da ideia ou do "ser" ausente, dito de outro modo ela torna presente algo que está ausente e assim permite aos sujeitos sociais (falando grosso modo) "entrar em contato" ou interagir com a coisa ausente por meio de sua representação. Ginzburg toma como caso emblemático as efigies dos reis medievais, as quais representam o verdadeiro corpo do soberano, assumindo o seu lugar e tornando-o presente ${ }^{19}$. Por esse prisma podemos assumir que a pintura histórica de Theodoro Braga não é um retrato fiel da realidade, o fato histórico não foi pintado tal como realmente aconteceu muito embora o senhor Braga pretendesse que os espectadores em 1908 e a posteridade constatassem que sua obra era uma reconstituição fidedigna do fato histórico. $\mathrm{O}$ artista paraense elaborou a sua versão do acontecimento e construiu uma representação do mesmo. Para isso ele recorreu a um conjunto de documentos e registros do período colonial. As fontes dessa investigação foram publicadas num opúsculo chamado "A fundação da cidade de Nossa Senhora de Belém do Pará: estudos e documentos para a execução da grande tela histórica pintada pelo autor e encomendada pelo benemérito intendente municipal de Belém Exmo. Sr. Senador Antonio J. Lemos”. Esse opúsculo foi escrito com a finalidade de ser apresentado em conjunto com a pintura o que é revelador das intenções do senhor Theodoro Braga: este não apenas confecciona uma representação do fato histórico, como também elaborou um meio de confirmar a veracidade de seu trabalho.

Ao expor minha tela Fundação da Cidade de Belém e com ela um opúsculo explicando-a e documentando-a, esperava eu, tal é a importância do assunto para nós, que todos que dele tratam viessem imediatamente armados de documentos irrefutáveis e esmagadores, cheios de luz e verdade, reduzir a cinzas o meu quadro e os meus estudos. (...) Nada inventei, nem fiz história:

\footnotetext{
${ }^{18}$ Para a leitura de tais questões são recomendas as obras dos historiadores Roger Chartier, Carlo Ginzburg e Ernst H. Gombrich.

${ }^{19}$ GINZBURG, Carlo. Olhos de madeira - nove reflexões sobre a distância. $1^{\circ}$ reimpressão. São Paulo: Companhia das Letras, 2001, p. 85-103.
} 
garanti o meu trabalho de uma fortaleza inexpugnável, ataquem-me e destruam-na, mas com elementos. (...) Dizer e não provar é não dizer²0.

No trecho acima, o artista belenense busca defender sua posição de estudioso da história afirmando que sua arte foi pensada a partir de um arcabouço documental e não inventada ao acaso. Em grande medida, Theodoro Braga procurou defender-se da contraposição de Arthur Vianna e do Barão de Guajará, os quais apontaram os erros históricos presentes na Fundação de 1908, notavelmente a construção do forte que na tela é apresentado sendo de pedra; tanto Arthur Vianna e o Barão afirmariam categoricamente que o material empregado para a construção do forte era a madeira, no entanto o senhor Braga não se renderia facilmente e mostrou-se disposto a confrontar a contraposição dos historiadores do período, tendo escrito em seu opúsculo uma extensa defesa da representação do forte de pedra. Não cabe aqui julgar se o artista foi ou não desonesto em sua criação imagética, o mais válido neste texto é reconhecer sua posição enquanto pesquisador, disposto a digladiar-se com seus contemporâneos, em favor se da sua obra artística. Esse posicionamento do pintor-historiador, essa necessidade em legitimar seu trabalho, configura novamente o caso emblemático de um profissional da arte que se traveste de investigador do tempo passado, o que já foi abordado nos parágrafos anteriores.

A questão da memória é outro ponto a ser ressaltado quando se analisa a Fundação. Esta tela - a qual ocupa um importante lugar na coleção de arte do poder público municipal e que foi pensada como um símbolo máximo da memória da cidade - é a reprodução (poder-se-ia dizer também a invenção) de um fato pretérito tomado como fundamental para a história de Belém e da Amazônia, portanto é sua função servir como memória visual desse fato. Levando isso em consideração é necessário atentar para algumas funcionalidades da memória. Pierre Janet nos chama a atenção para a função social da memória, sua propriedade de comunicar algo a alguém e principalmente, sua capacidade de transmitir um acontecimento a quem não o testemunhou ${ }^{21}$. Além dessa função social a memória também é elemento essencial para a construção e \ou manutenção de identidade, seja ela coletiva ou individual ${ }^{22}$. A tela de Theodoro Braga abarca em grande medida essas propriedades da memória. Em primeiro lugar ela transmite à sociedade belenense do século XX um

\footnotetext{
20 A Província do Pará, 11 de maio de 1909, p. 1.

${ }^{21}$ LE GOFF, Jacques. História e memória. $5^{\circ}$ edição. Campinas, São Paulo: Editora da Unicamp, 2003.

22 LE GOFF, Jacques. História e memória. $5^{\circ}$ edição. Campinas, São Paulo: Editora da Unicamp, 2003.
} 
acontecimento do passado e nesse caso trata-se de um passado tão antigo e distante que, de modo natural, ninguém poderia relembrar; logo a tela histórica é instrumentalizada para preencher uma lacuna na memória da sociedade, é a representação tornando presente o fato que está ausente. Em segundo lugar a Fundação de Theodoro Braga - ao reproduzir um passado pressuposto como comum ao povo belenense - produz uma identidade, uma memória coletiva para a metrópole paraense e ao mesmo tempo torna-se um recurso para o poder público cristalizar a imagem que se desejava da origem da cidade "belle-époqueana".

O amálgama de tantas instrumentalizações de uma pintura revela o quanto há de significativo nas obras iconográficas de Theodoro José da Silva Braga, e também demonstra que a sua utilização para as análises da sociedade amazônica, notadamente de seus membros ilustrados, líderes políticos e seus intelectuais, pode ser bastante frutífera. $\mathrm{O}$ uso das artes visuais na investigação histórica dos grupos letrados da Amazônia e seu relacionamento com o poder público é bastante interessante no que toca ao entendimento dos projetos e discursos que se destacavam no meio ilustrado paraense e sua percepção de como deveria ser interpretada a história de Belém e da Amazônia. No caso da Fundação de Belém de Theodoro Braga temos a composição de um discurso sobre as origens da sociedade amazônica, o qual se pretende cristalizador de uma memória do passado e representativo de um fato histórico. Trata-se de um discurso que é elaborado não pelas letras e sim pelas tintas dos pincéis, os quais contam uma história. Uma narrativa visual que visa recriar o passado e, ao mesmo tempo, ocupar um lugar especial na história de Belém encantando seus "leitores" com suas cores e com sua estética.

\section{Referência bibliográfica}

BRAGA, Theodoro. "A arte no Pará (1888-1929) retrospectiva histórica dos últimos trinta anos”. Revista do Instituto Histórico e Geográfico do Pará, vol. 8, 1934, p. 149159.

BRAGA, Theodoro. A fundação da cidade de Nossa Senhora de Belém do Pará: estudos e documentos para a execução da grande tela histórica pintada pelo autor e encomendada pelo benemérito intendente municipal de Belém Exmo. Sr. Senador Antonio J. de Lemos. Belém: Secção de Obras Raras d’ A Província do Pará, 1908. 
BURKE, Peter. Testemunha ocular: história e imagem $.2^{\circ}$ edição. Bauru, São Paulo: EDUSC, 2004.

COUDREAU, Henri. L'Avenir de la capitale du Pará. Anais da Biblioteca e Arquivo Público do Pará. V.8. Belém, 1913.

FIGUEIREDO, Aldrin Moura de. Eternos modernos: uma história social da arte e da literatura na Amazônia, 1908-1929. 09/11/2001. 315 folhas. Tese de doutorado. Instituto de Filosofia e Ciências Humanas, Unicamp, Campinas-SP, 2001.

GINZBURG, Carlo. Olhos de madeira - nove reflexões sobre a distância. $1^{0}$ reimpressão. São Paulo: Companhia das Letras, 2001, p. 85-103.

LE GOFF, Jacques. História e memória. $5^{0}$ edição. Campinas, São Paulo: Editora da Unicamp, 2003.

PANOFSKY, Erwin. Significado nas Artes Visuais. $3^{0}$ edição - $3^{0}$ reimpressão São Paulo: Perspectiva, 2009.

PARET, Peter. Imagined Battles: Reflections of War in European Art. Chapell Hill: University of North Caroline Press, 1997.

SARGES, Maria de Nazaré. Belém: riquezas produzindo a Belle-époque (1870-1911). $2^{\circ}$ edição. Belém: Paka-Tatu, 2002.

SCHWARCZ, Lilia Moritz. "Os franceses no Brasil de D. João”, REVISTA USP, n.79, São Paulo, 2008, p.54-69. 